Kohl: a Journal for Body and Gender Research

Vol. 2, No. 2 (Winter 2016)

\title{
The Cul-de-Sac of Postcolonial Theory: Negotiation or Negation?
}

Shereen Abuelnaga

\begin{abstract}
:
The escalating wave of migration and its discontents that the world is witnessing now challenges some aspects that form the backbone of postcolonial theory through revealing the inefficiency and invalidity of all the previous givens. Policed borders render the concept of hybridity and the horizon invalid. The attempt at eluding the politics of polarity could not survive the discursive and physical practices of several dislocated localities. Consequently, the "contact zone" that has always been the pride of the West, upon the assumption of hybridity, is shrinking now, if not fading. What should have been cultural negotiation came down to be cultural negation. This paper reads the status of the women asylum seekers who are locked in Yarl's Wood Center in the U.K. as an example of the stark violations practiced against immigrants and refugees in general, and in the case of women, as an example of turning the female body into an arena onto which conflicting power relations are inscribed. However, the main goal of this reading is to prove the failure of postcolonial theory to cope with the fierce return of borders, material and symbolic. To do this, the paper assumes that the life stories of the women stand as a text/narrative that yields itself to analysis.
\end{abstract}


In spite of all the complications, restrictions, traumas, and tragic stories of death in the Mediterranean, the current waves of migration do not seem to have a foreseeable end. While the reasons behind this continuity are both varied and painful, they have one common feature: the immigrants are leaving failed states, ex-colonized or postcolonial spaces that have been devastated by struggles over power, due to the play of internal and international forces that are governed by the rule over human and economic resources, for what they deem to be welfare states and utopian places at least in the sense of security and absence of threat. The question of power, then, is essential in this context. It is the pillar without which no huge waves of mobility, immigration, and displacement could have happened. While mobility of various forms - of people, culture, tourism, services - across borders has been considered a mark of globalization (Bauman, 2000; Appadurai, 1996), it has definitely lost its glamorous core definition recently in a world that has re-enforced national borders, ones that are not porous anymore.

Therefore, the act of crossing borders now is bound to re-define the state of citizenship of the crosser. Certainly, this shift in citizenship is not applicable to all those who cross the borders. I am referring in particular to the people who are "forced" to cross, or rather, to escape from dire circumstances and civil wars, such as Iraqis, Syrians, Libyans, and Palestinians. Once those citizens cross the borders of their home countries - a difficult trek in itself - they simply stop being citizens. They become "refugees." They lose all rights to citizenship and they acquire, involuntarily, the state of the "inexistent" that Alan Badiou has explained as a type of political state in itself. He states: "Every object, considered in its being a pure multiple, is inexorably marked by the fact that in appearing in this world it could have also not appeared" (2009, p.322). In other words, forced mobility has turned citizenship into a contingent state. Although such an act of migration always has two points, the word metaphorical implies imagined in the metaphorical sense since sometimes the act entails more than one point, that of departure and another of arrival, in both points borders are crucial; they function, simultaneously, as an exit and an entrance. Yet, what remains as a fact is that the act of crossing borders has a teleological end that is deferred incessantly. The imagined point of arrival never comes true, and so the binary of departure and arrival is never fixed. That the imagined "other" place - other than camps or prison or deportation is always deferred and postponed is a strong challenge to the stability of meaning.

It suffices to think of the Syrian crisis and to watch the flood of images that circulate virally in the media, where many powers are striving to "solve" the Syrian question through bombarding the "bad guys" and vice versa, to realize that crossing borders has become a life saviour, albeit a temporary one, and even if camps are all that is waiting on the other side. While Syrians form the highest number of refugees currently, many other Third World countries continue to do so. Put differently, the legacies of past colonial governance combined with the toxic mix of a neo-liberal economy, the rise of religious fundamentalism and the desire to control are dominating the scene. The authoritarian side of Third World rules crush its own people and push them to land in a boat that could capsize in less than half an hour. Yet, even in such crises there is no equality. While men and women flee civil wars, very dire economic circumstances, physical torture, arbitrary arrests, mass killings, women have to face a double jeopardy. Yazidi women are a case in point; although not the only one. While fleeing from a despotic regime with all its repercussions, women also flee to protect the very special measures usually taken against them against the backdrop of gender. These include but are not limited to: rape, sexual harassment, forced marriages, house incarceration, forced abortions, vilification, and forced conversion to another religion. We can only think of the Yazidi women who are taken as sabaya (spoils of war) and 
forced to convert to Islam only to become sex slaves (similar to the comfort women during WWII) for the ISIS men. In the January 2014 report issued by Women for Refugee Women, ${ }^{1}$ figures and stories are shocking:

33 , or $72 \%$, of the women we spoke to said that they had been raped as part of the persecution that they were fleeing. For instance, one woman was arrested by government forces in eastern Democratic Republic of Congo under suspicion of being a rebel, held in prison with her legs chained apart, and repeatedly raped by soldiers over a period of weeks (Detained, 10).

Although such figures are telling about the situation, the fact remains that there are no specific or accurate numbers in relation to migrants. One cannot even figure out the percentage of men to women and children. Most reports deal with random samples and testimonies that prove that people survive but do not live. What we are certain of is that Third World women flee from the legacies of corruption, brutality, and authoritarian measures to which postcolonial theory has reacted extensively a long time ago, and patriarchy, which feminist postcolonial theorists have declared to be an essential component that has been glossed over by postcolonialism. Yet, postcolonialism has reacted to and engaged with different material conditions that were shaped by a different historical and political factors.

As proven by the current political situation on borders, e.g., Greece, Macedonia, Hungary, and Austria, women flee from one patriarchy only to be met by another, concealed in the form of legal measures. Certainly, asylum entails a legal process; however, there is more to it. We cannot ignore the cultural, socio-economic and political factors that govern the "legal" process of granting asylum and put those women not only "under Western eyes" but also under the mercy of global capitalism and political power structures. My concern in this paper is focused on the specificities of forced migration. It is a form of migration that is based on the "either/or" equation where choices are not available and certainly agency is denied. Alice from Cameroon, who was detained upon her arrival to the U.K., has testified that "There is no law in detention. You feel that the guards apply the law according to their mood and prejudices. They inflict their own feelings on the women in there and there is nothing to stop them. Yarl's Wood is a lawless place" (Detained, 18-19).

It is an established fact that ignoring differences has been the battleground of feminist postcolonial theory. Thus, all contributions were reacting to the tendency of Western liberal feminism to homogenize under the label of "sisterhood." Chandra T. Mohanty, Audre Lorde, Uma Narayan, and others have been the pioneers in the field. Yet, the question remains: how could this huge literature of the feminist postcolonial serve to solve and disentangle the complex hierarchical power structures in which the women who are forced to migrate are trapped in? While this paper does not claim that it is going to find solutions - since the situation mostly has to do with the anti-immigration policies and profitable capitalist organizations - it is bent on demystifying certain mainstream postcolonial concepts that have always been celebrated by and adopted as methodological approaches in the academic scholarship of the MENA region.

\footnotetext{
${ }^{1}$ Women for Refugee Women is a UK based NGO that challenges the injustice experienced by women who cross borders to seek safety. For a detailed overview of their work and activities visit their website: www.refugeewomen.co.uk
} 
Having been trained in the field of literature and literary criticism, it surprises me to see the number of theses that sanctify, I venture to say, the classical concepts of postcolonial theory without any trace of re-evaluating or revising the validity of their hypotheses. ${ }^{2}$ When feminist postcolonial theory is adopted as a method of approach, it serves to focus on the double jeopardy and colonization of women displayed in the form of marginalization or stereotyping. In other words, the research produced currently in the Arab academia neither engages with nor problematizes the changing nature of times. That postcolonial and feminist postcolonial theory are "applied" without any nuances or challenges is highly alarming. Certainly, the theory could function brilliantly with an Achebe text, an Adichie novel, or alZayyat's debut. However, to leave the bulk of theory intact makes it valid for all times and places, which is far from true. Hence, the cul-de-sac of postcolonial theory.

If we agree that theory responds to a specific socio-politico-cultural context, then the process of questioning the theoretical underpinnings cannot be avoided or postponed. To legitimize the process of questioning and testing the validity of theory, there must be a backdrop against which to measure that. Thus, the paper will investigate the case of the detained women in Yarl's Wood Center in UK 3 through reading their testimonies, a narrative text in themselves. My purpose is not to reveal postcolonial theory neutrality (and blindness) to gender, as much as to take issue with its solid trajectory that has become part and parcel of the mainstream field. Since postcolonial theory entails a huge array of concepts, I will be selecting three concepts as my focus: borders, hybridity, and the horizon. I will be reading a materially-specific situation through these concepts to delineate the shortcomings of the theory.

\section{Borders: What are they good for?}

The geographical borders stand as the first obstacle that immigrants have to deal with, whether legally or illegally; simultaneously, these borders represent the symbolic demarcation between selves and other selves, and have been theorized as the space of neither here nor there. Theoretically and ideally speaking, the borders should be "the shared ground" (Mohanty, 1989, p.21), or rather the middle ground that Gloria Anzaldúa has theorized extensively (1987) in her much cited book Borderlands/La Frontera. Certainly, the Chicana theorization sounds attractive and appealing, yet, reality hits. To explain, recently, the control of borders, as mentioned above, has gained political priority. They are the barrier, filter, shield, protection, and sign of power. However, of more importance is that borders themselves have become a zone of implementing the law (closing the borders, deporting refugees into camps, denying entrance, etc.) for security reasons that wave the flag of combatting terrorism. Concomitantly, the discourse of human rights erupts forcefully with reference to refugees rights. While

\footnotetext{
2 In departments of languages of Egypt, especially the English language, Postcolonial aspects like hybridity, resistance, transformation, and interpolation, to name a few, are taken in a copy and paste method to render literary analyses of several novels, poems and plays written in English. We have, yet, to wait for a thesis proposal that questions the validity of such aspects in the $21^{\text {st }}$ Century.

3 Yarl's Wood Centre, opened in November 2001 (one month after the 9/11 attacks). Although in 2007, control was signed over to Serco, a neo-capitalist company par excellence, the Centre never stopped being far from controversy. Ironically, the Centre perceives itself to be "a fully contained residential centre housing adult women and adult family groups awaiting immigration clearance", it is definitely a detention centre. For more details on the Centre, see the website: www.yarlswood.co.uk
} 
the international arena is replete with reports released regularly, from the UNHCR (the UN Regugee Agency) for example, where figures are followed by recommendations, the painful reality of refugees does not change. . Borders become a site for conflicting discourses where the legal part immediately takes over to centralize the inexistent, the outsider, the stranger and the different. Because of that, borders have become the first zone where immigrants' subjectivities are tested, challenged, formed, and transformed.

Borders have become the terrain where repeated confrontations between immigrants and the security forces take place, and where the myth of cultural purity and authenticity, in addition to the legal terminology, resurface only to justify violence and barriers erection. Indeed, it all goes back to capitalist power structures and conflicts where refugees now stand as the bargaining card, as shown for instance in the fate of Syrians who migrated to Europe through Turkey and had to go back to Turkey because of a deal between the latter and the EU. The more such confrontations take place, the more memories of a colonial past are triggered, and the more binaries are re-erected: centre/periphery, First World/Third World, and white/non-white. This is how the legal side rubs human rights violations. Europe has hastened to block its borders to the extent that Timothy Garton Ash, the political analyst, comments in The Guardian that: "what we are seeing in 2015 is Europe's reverse 1989" (Ash, 2015). He explains that the demolition of the iron curtain started by cutting the barbed wires between Hungary and Austria. Now it is Hungary, its prime minister in particular, Viktor Orban, that is calling for keeping Muslim migrants out, in order to "Keep Europe Christian." (Puhl, 2015) In November 2015, Macedonian police prevented migrants from crossing the borders to Greece, with the result of forty injured (Alderman, 2016).

As catastrophic as it is now, borders have become part and parcel of a pressing material reality that is pushing the world into a complicated process of re-mapping, and is transforming the meaning of detention places to include camps, centres, and secluded areas. Immigrants are stuck in the middle (literally and symbolically), or rather caught between binaries: stasis versus travel, war versus peace, certainty versus interrogation, Utopia versus dystopia, and sameness versus difference. Most importantly, the borderland is Janus-faced: it signifies the roots left behind, traditions and customs, and the intercultural routes taken to move into another culture's (Clifford, 1992). Reaching or crossing the borders marks the beginning of a long series of cultural politics. Whether allowed in legally or smuggled illegally, the immigrant/refugee is always in the state of the included-out. They are constantly forced to re-locate and re-consider their position not only physically and politically, but also psychologically. Borders are already populated with ex-citizens, that is, "inexistent" who even when allowed in or granted the right of abode, remain as included-outs. I am borrowing this concept from John N. Erni (2015), who details it as follows:

This is not to say that inclusion is purely imagined or fake for the incorporated persons who have successfully claimed or counter-claimed their citizenship papers from the perspective of the law. It is to say, rather, that for some time now, citizenship management has been practised through the state of general inclusion-outness and this changes everything that used to be called politics (as well as anything we may understand as looking at citizenship rights through/and politics and vice versa (p.5). 
The point Erni makes is that citizenship management itself has been characterized by this state of being included-out. That is to say, while the classic form of border control and legal procedures are still there, perhaps in more restrictive forms, the concept of "belonging" (p. 6) has become instable, nebulous, and thus necessitates survival all the time. That is why it is important to read the web of identity politics that immigrants experience once they cross or transgress the geographical borders. We must also remember that as much as immigrants are bound to effect a change in the world they move to, they are also changed, whether by means of power, containment, assimilation, or even enforced binaries. In a nutshell, the constant movement and process of mobility make up the present shifting world, and form what has been theorised as the hybridic modern/postmodern moment (Friedman, 1998), what Arjun Appadurai has confidently called the "global ethnoscape" (1996, p.48), or what Bauman (2000) has labelled liquid modernity. How valid are all these terms now? The current situation with all its consequences and complications necessitates a re-examining of the entire postcolonial theoretical paradigm.

Crossing the geographical borders is not the end of the story; it is indeed the beginning. Crossing geographically does not guarantee the cultural crossing or a stable feeling of belonging. This is because the horizon that lies behind the process of crossing renders the issue of hybridity and reception more complex due to all the potential possibilities that are either invested or wasted. The spaces in-between, the neither here nor there, the contact zone - all labels for the concept of liminality - function as a site of initiation rites. It is exactly at this site, where the horizon lies ahead and "home" lies behind, or rather roots and routes (Clifford, 1992), that the first interaction takes place. It is along these routes that citizens with particular experiences and histories become inexistent; and instead of being subjects they become subject-ed to specific regimes of power and representation. This space of cultural encounter has been taken to be a space of production and synthesis; it is a space that used to allow for new formations of subjectivities. Friedman (1998) has aptly explained that it is more than "a longed for or resisted dream that transcends the realities of power. The contact zone where differences meet is as real and as significant a part of cultural formations, including the formations of identity, as the spaces of difference" (p.104). In light of the resurfacing of all classical (and orientalist) dichotomies, one realizes that Friedman is referring to a Utopian past.

Although most theorists of post-colonialism have confirmed the positive effect of such encounters (Bhabha, 1994; Gilroy, 1993; Clifford, 1992; Appadurai, 1996), I argue that crossing the borders recently has led to an extreme violent encounter, replete with the classic colonial rhetoric of binaries: oppressor/oppressed, cultural purity/cultural mixing, and most important male/female. Violence and apprehension, negation and not negotiation, begin even before crossing the borders, whether geographical or cultural. My argument revolves around specific concepts that form the backbone of the postcolonial theory and intersects with diaspora and migration theories: the borderlands, the horizon as "a principle which does not dispense with boundaries altogether but inhabits them, utilizes them, incorporates them in a different way" (Ashcroft, 2001, p.184), and forms of hybridity. As for the latter, I am in total agreement with Robert Young (1995) that "there is no single, or correct, concept of hybridity" (p. 26). While class and race definitely underlie the crisis of immigrants, gender and women's bodies are also essential factors of analysis to understand how power relations re-inscribe what Erni (2015) calls the inclusion-outness. How this state is enacted on the female body is the key to prove the shortcomings of postcolonial theories to interpret the current happenings. In addition to many other 
factors, the gendered discursive practices by and against immigrants and refugees have taken the theoretical postcolonial episteme to a cul-de-sac.

\section{The blockade of the horizon}

Borders and intercultural encounters take place in narratives; to be more accurate, they do not become an issue except when narrativized as a story. No theoretical assumptions can be made without a concrete event that in turn becomes a story. Therefore, in order to think concretely of the cul-de-sac of the postcolonial theoretical mind this paper deals with some life stories of the detained women in Yarl's Wood Centre as a narrative that exemplifies clearly the interplay of power relations that are enacted, by both outsiders and insiders, through gender. The narrative presents a gendered discourse that consolidates the concept of the included-outs. Also, it clarifies how the female body has become the main battleground on which belonging and exclusion are inscribed.

The infamous Yarl's Wood Immigration Removal Centre is located in Bedfordshire, England. It is a detention centre, among thirteen other centres, for foreign nationals prior to their either deportation from the UK or granting them asylum. Its population is, and has been, mostly women. In 2015, the nonprofitable organization of Women for Refugee Women issued its report (2015) where the testimonies of 38 ex-detained women are published. The women testified that they were sexually assaulted by the staff male members of the centre, and their privacy was violated due to the inhuman ways of surveillance like being searched and touched by men, or being watched naked and in the bathroom. Those women, themselves survivors of rape and sexual violence, had come to seek protection; instead, they ended up detained in this centre. The experience of women and their testimonies are reminiscent of the Guantanamo Bay Prison where severe surveillance by locking prisoners into cages was part of the humiliation and pressure process. Perhaps it all comes from the Foucauldian legacy of his panopticism. That is, complete transparency and absence of privacy mean total control. For example, one of the women said: "When I was seen on the toilet I felt so scared. The anger I had when this happened, it made me feel so frustrated;" and another confirmed the feeling: "There was nothing I could do. Four men watched me while I was naked. They wouldn't cover me. I was so vulnerable" (WFRW, 2015, p. 12).

These testimonies and life stories show that gender is the main dynamic upon which power relations are structured. While it is an oversimplification to assume that these violations are caused by fixed stereotypes, one cannot overlook the fact that such violations form the initial contact between two cultures (or more). I argue that the multiple positionalities that are the result of power relations have blocked the possibilities of the horizon; such blockade has generated nonetheless a "third space" (Bhabha, 1994) that was enacted on women's bodies through what Sharon Marcuse has called "the gendered grammar of violence" $(1992,392)$. Whether such an encounter in the emerging horizon has led to negation or negotiation is to be further investigated. Ironically, the notion of the "third space" as advanced by Bhabha implies a positive result of the encounter. According to Bhabha, it is the indeterminate spaces in-between subject-positions that are lauded as the locale of the disruption and displacement of hegemonic colonial narratives of cultural structures and practices (Bhabha, 1994 \& 2000). Bhabha posits hybridity as such a form of liminal or in-between space; he goes as far as stating: 
To that end we should remember that it is the "inter"-the cutting edge of translation and negotiation, the in-between, the space of the entre that Derrida has opened up in writing itselfthat carries the burden of the meaning of culture. It makes it possible to begin envisaging national, antinationalist, histories of the "people." It is in this space that we will find those words with which we can speak of Ourselves and Others. And by exploring this hybridity, this "Third Space," we may elude the politics of polarity and emerge as the others of our selves (2006, p.157).

The Yarl's Wood Centre is a form of prison where the women are detained and banned from communicating with the outside world. It is as if they have not crossed any borders. The detention centre has become, paradoxically, the contact zone. Simultaneously, it marks the frontier between those "suspicious" women and a community that seeks protection of its authenticity, security, and economic resources. Thus the centre has become a form of vilifying the "other," which is the crudest example of setting boundaries. It must be noted that the women detained in this centre are denied the opportunity to any form of agency that could lead to "La conciencia de la mestiza" (Anzaldua, 1987, p. 77) that allows the formulation of a thriving subjectivity sin frontera, i.e., without borders. There is no tex-mex, no contact, no interaction. The very fact that this centre exists implies that the cultural encounter that was supposed to take place has immediately generated a process of negation.

The testimonies of the women reveal the complicated process of subjectivity formation. Having moved to the UK, this woman is located (or detained?) in a space that does not allow any exchange. She is unable to experience the common position that Stuart Hall (1990) believes to be one of the vectors onto which cultural identity is formulated, i.e., "to discover, excavate, bring to light and express" (223) the common historical experiences that endow "one people" (223) with stable and continuous frames of epistemological meaning. Instead, what is experienced is rupture, discontinuity, and an enforced regime of representation, which connotes power. The dialogic interaction that Susan Friedman (1998) compares to the Freudian game of fort/da - a game that marks the first signification for the child - is totally absent. The harm is actually double-edged. It is not only the women who are denied any exchange, but also the other selves. Both parties (which I prefer to call selves and other selves instead of self and other ${ }^{4}$ ) are denied the opportunity "to discover" and "to excavate" any common zone; what is left, then, are women's bodies where the women are subject-ed to new regimes of power.

Clearly, the barriers behind which these women are detained serve to preserve difference rather than negotiate sameness. A long time ago, Henrietta Moore has defamed these barriers as "brutal and bloody" (1994, p.1). Because these borders/boundaries/barriers are not permeable or porous, difference becomes a marker of superiority, hence the denial and absence of syncretism. The original process that postcolonial theorists have been hoping and paving the way for is the erection of boundaries that is usually followed by an involuntary process of dissolution, and the borderlands that become a space of energy as they lead to questioning fixities and to releasing change (Ashcroft, 2000;

\footnotetext{
4 The concept of self/other is widely used and has become a popular binary in the field of identity politics. However, it is a binary that not only implies but also enforces alterity where one part of the binary is privileged. The use of self and other selves, instead, implies equity and endows both parts with an autonomous subjectivity.
} 
Pratt, 1992). In his Post-Colonial Transformation, Bill Ashcroft (2001) has even theorized the process of transformation that is bound to affect the discourse of power from within. Reality has surely demystified all such theories. In 2014, the detention forum, based in UK, conducted a campaign called "Unlocking Detention." The purpose was to give voice to the voiceless detainees and to reveal the "real" meaning of detention for the parliament that decided to conduct the first inquiry into immigration detention in the UK (Ohtani, 2015). Eiri Ohtani, a member of the campaign, states that the inquiry, which was supported by 200 evidence collected from different cities and towns, has revealed unexpectedly that "detention does not stop at the gates of the detention centres, it continues to take its toll long after people have been released" (Ohtani, 2014). Indeed, detention is not about physical incarceration only, it goes beyond that. Breaking the spirit and destitution are the corollaries of the detention experience especially with all the women who have already suffered in their home countries. Some of the women testified that the feeling of humiliation: "I never felt safe. Because I was raped before in my country. I was scared the same thing will happen to me. I was so scared I hardly left my room;" and another mentioned specifically her loss of hope: "I felt like nothing. I lost hope and courage, that I was degraded to such a condition. All these people watching me" (I Am Human, 2015, p. 12). Shockingly enough, these women were on suicide watch (I Am Human WFRW, 2015, p. 11).

In the paradigm of postcolonial theories, boundaries are always resisted and incessantly transgressed or crossed to reach what Ashcroft (2001) terms as "horizonality." The horizon is related to expansion as opposed to contraction, and possibility as opposed to impossibility. Therefore, "horizonality is the only way in which the predominance of the boundary in Western thought can be resisted" (Ashcroft, 2001, 183). The possibilities - including those of belonging - awaiting the detained women or even exdetained are blurred and nebulous since they are enmeshed in a web of power relations that, unfortunately, take the postcolonial theoretical discourse back to a point prior to the publication of Orientalism in 1978, only ten years prior to Anzaldúa's book (1987). To explain, there is an inner horizon, and in this case it is materialized in the secluded isolated centre, where sexual harassment and abuse take place. The outer horizon is the wider context that has called for the establishment of the detention centres as a principle. The centre becomes a marker, and even a discursive practice of antiimmigration policies. One has to disagree with Ashcroft who has described the horizon with a confident tone as "a permanent, taken-for-granted aspect of our relationship to the world;" and that is why "it is the cultural insistence on boundaries rather than the perception of horizonality which seems anomalous or imposed" (2001, p. 185). According to material reality, the denial of the horizon is the default, which goes in accordance with the politics of inclusion and exclusion. The detained women are included-outs par excellence. Therefore, Ashcroft is perfectly right when he assumes that the inability to contest the politically imposed boundaries "undermines the project of post-colonial resistance." He reiterates "a recognition of the regulatory power and discursive function of boundaries is an essential basis for the development of post-colonial horizonality" $(2001,186)$. I believe that this political and epistemic "recognition" is what theory must work on more in the current situation.

Overlooking the importance of this recognition has so far rendered women's bodies a contesting arena and a conflicting site where all the politics of exclusion are inscribed, even if inclusion is the official state. In the January 2015 report issued by Women for Refugee Women, ex-detained women in Yarl's Wood Centre gave their testimonies. Although all the stories and testimonies are heart-breaking, Rechel's story, in particular, tells a lot about the humiliation that results from detention. Rechel is from 
St.Vincent and now lives in Leeds. She has spent eight months in Yarl's Wood Center. She was raped in her country by a gang to teach her father a lesson over drugs money. She came to the UK and had to spend a sentence of 12 months in and after her release she was arrested again and dragged by force to Yarl's Wood. There, began her new ordeal:

I became majorly depressed. I was then diagnosed with post-traumatic stress disorder and rape trauma syndrome. I remained in Yarl's Wood for another eight months. Pure shame and disgrace. I thought prison was bad but Yarl's Wood pushed me to the point of wanting to commit suicide. I went on to become a major selfharmer. I was harming myself to cope with things. I suffered with people invading my space. Officers would enter your room behind your back, go through your bed, your underwear and these are male officers. I felt raped all over again. And while there I told the doctor I was raped at 15 and she told me it was a private matter. I felt like ending my life. Yarl's Wood made me feel like life itself wasn't worth living anymore. It is faith that kept me going and the fact that I shared a room, or today I would not be here to tell my story, I would have been a dead woman. I had a doctor come in and examine me and assess my situation and the doctor sent a report to my caseworker letting him know that I was I was being watched while at Yarl's Wood and the effect it had on me. He ignored it. I was advised to give a copy to the healthcare at Yarl's Wood and they themselves ignored it while my health deteriorated. I have to thank the judge that released me because I had already written my suicide note in preparation to killing myself. I would never wish for any human being or even a dog to be in a place like that. It is not humane, it is not right and it leaves you scarred for life. I don't know how to recover from this torture. (I Am Human, 2015, p.13)

Rechel's story proves that the violations exercised on the detained women in Yarl's Wood Centre could be interpreted against the backdrop of power relations where superiority is played out on race, ethnicity, class, religion, and most important gender. Also, the horizonality was blocked and the centre functioned as an isolated place by force. Condemning violence against women and the unjust incarceration is of course part of advancing a politically correct argument. However, one should also question the underlying meaning of such violations. To do this, we must remember the warning of Ella Shohat, "a celebration of syncretism and hybridity per se if not articulated in conjunction with questions of hegemony and neo-colonial power relations, runs the risk of appearing to sanctify the fait accompli of colonial violence" $(1992,109)$. Can we venture to accept the presence of "neo-colonial power relations" in this context? It is here that understanding the outer constituents of the horizon pushes the argument forward.

In a ragtag combination, the intensification of socio-economic, racial, political, and ethnic factors could very possibly render the new space "a neo-colonial power" with the concept of inclusion-outness in the heart of the scene. The term "space" does not mean place, the Center, but all the geopolitical axes that constitute a certain community, and where questions of power are invoked. Space is "not a static or empty essence, but rather the spatial organization of human societies, the cultural meanings and institutions that are historically produced in and through specifically spatial locations" (Friedman, 1998, 109). The geopolitical space, thus, forms the outer horizon where the women are detained. The Centre, with all its activities, is not only a space but also a result of the current Right-wing discourse that has rashly and dangerously stigmatized immigrants. As dangerous as this could be, it is equally 
catastrophic to turn women's bodies into a space where the discursive could materialize. To be more specific, the corporeal bodies of women came to the foreground - although detained - as the medium through which the encounter erupts forcefully. The discourse about women that relegates them into the state of included-outs - which in itself part of the representation system - has contributed highly to bringing the crisis into light.

Sadly enough, some European feminist movements got trapped in the Manichaean binarisms and dichotomies that have been recharged by the revival of nationalism; a fact that makes Inga Ingulfsen ask rhetorically "Why aren't European feminists arguing against the anti-immigrant right?" She answers that they "face immense pressure from the dual temptation of cultural fundamentalism and cultural relativism;" and she continues to advise that

It is time to forge a different, more inclusive movement. One that is not afraid to engage in difficult conversations about culture. Divorcing from multiculturalism and flirting with the extreme right will only perpetuate the notion that European feminists see equality as their culturally exclusive privilege, and if the historical record has taught us anything, it is that when feminism fails to be inclusive and intersectional it is easily appropriated by conservative political forces and used to legitimize discriminatory policies (Ingulfsen, 2016).

The Yarl's Wood Centre has opened in 2001, with Serco operating the contract for the UK home Office since 2007. Serco is a profitable global corporation, and among its services is the management of immigration centres and prisons. After a quick browsing of the company's website (www.serco.com), one starts getting convinced of how the company has "hovered up outsourced government contracts," in John Harris' words (Harris, 2013). It is the equivalent of the symbolic phallus which functions as "the signifier intending to designate as a whole the effects of the signified" (1966, p. 77). The women, as the "signified," became the other whose position endows the masculine self - the guards - with a shield that could stand to the "neo-colonial power." It is at this moment that women's bodies became the site where the battles of all the included-outs - as designated by power - are played out. In a way, women symbolize the body politic of a peripheral state: "Women are typically constructed as the symbolic bearers of the nation but are denied any direct relation to national agency" (Anne McClintock, 1997. 90). This is how the whole legacy of colonialism is triggered.

Which kind of hybridity could take place within such a polarized frame? Certainly the type of hybridity that governs the whole situation between the Serco company and the detained women is strictly economic (the original motivation of colonialism). At the same time, there is a geopolitical dimension that should not be overlooked, that is, migration and border crossing are happening in a certain historical moment that denies any balance between roots and routes on one side, and strips the migrant from any state of citizenship. The expectations and theorizations of James Clifford (1992), Homi Bhabha (1994), Stuart Hall (1990), Paul Gilroy (1993), and Arjun Appadurai (1996) are blown by turning the female body in the Centre into a site of clash, transgression and aggression. With the female body turned into an arena onto which differences are inscribed, the taken-for-granted and celebrated concept of hybridity, along with all its corollaries, reach a cul-de-sac. Hybridity as a concept is not "celebrated and privileged as a kind of superior cultural intelligence owing to the advantage of inbetweeness, the straddling of two cultures and the consequent ability to negotiate the difference" 
(Hoogvelt, 1997, p.158). The horizon is blocked, even if it is opened again through official investigations of any sexual abuse.

\section{Cul-de-sac versus the exit}

The feverish scene of forced migration has brought back to the forefront the issue of identity in its most classic manifestations: similarity and difference. The rising wave of this form of migration and postcolonial theoretical concepts have produced each other as mutual blind spots. In the past two decades, postcolonial theory (-ies) has been revolving around negotiations of identities and shifting the monolithic epistemic concept of power into a space characterized by multiplicity where new forms of citizenships could thrive. The unexpected and sudden failure of several rules in the Third World, and the eruption of civil wars in many others, has resulted in not only an economic crisis, but also a conspicuous negligence of universal human rights. While there are many democratic voices that take issue with all measures against immigrants and work hard to alleviate borders' control and policing, the opposite discourse still maintains power because it puts the argument of the economic crisis and security control into the service of its logic. Hence, the negation of differences and the closure of material and symbolic borders. This result stands in stark opposition to what Young has theorized (1995) about hybridity that "wherever it emerges it suggests the impossibility of essentialism" (26). With the forceful re-inscription of borders - policed and symbolic - hybridity, or rather "hybridity-talk" (Friedman, 1998, p. 92) becomes just an ineffective discursive practice that hides a new hegemonic political project where borders are re-mapped and power relations are consolidated.

Certainly, men and women pay a dear price in such a global crisis. Yet, it is always women who pay the double price on the basis of conflating sex and gender. The crisis has revealed, among many other things, that women are still taken to be the markers of identity where the body becomes the arena on which all positions are registered. That all differences, conflicts, power relations, are enacted on women's bodies on and beyond the borders prove that postcolonial theory should start a process of self-evaluation and perhaps self-critique. The narrative of the detained women in Yarl's Wood Centre proves the inability to use postcolonial theory as an analytical approach. The theory is in a dire need to revise the new forms of mobility that has come into being as result of global capitalism. The latter turns refugees into non-existent and included-outs citizens who are trapped in a state of endless limbo. While it is the responsibility of academic humanities departments to engage with the theory, it is also of paramount importance to find an alternative approach to the current crises. Otherwise, the postcolonial theory that we have worked with for so long will be relegated to the realm of history of poststructuralism, recalled within the confines of classrooms. What we are witnessing now is a cul-de-sac of postcolonial theory exhibited in the dominance of negation and absence of acculturation. The exit requires a re-vision that cuts across cultural theory and migration studies. 


\section{References}

Alderman, L. (2016, 10 April). "Macedonian Police Use Tear Gas to Stop Migrants at Border." The New York Times. Retrieved from URL: http://www.nytimes.com/2016/04/11/world/europe/macedonia-greece-migrants-refugees.html

Anzaldua, G. (1987). Borderlands/La Frontera: the new mestiza. San Francisco: Aunt Lute Book Company.

Appadurai, A. (1996). Modernity at Large: Cultural Dimensions of Globalization. University of Minnesota Press, Minneapolis.

Ash, T. G. (2015, 29 November). "Europe's walls are going back up: it's like 1989 in reverse." The Guardian. Retrieved from URL: https://www.theguardian.com/commentisfree/2015/nov/29/europe-2015-walls-1989-parisrefugee-crisis

Ashcroft, B., Griffiths, G., and Tiffin, H. (2000). Post-Colonial Studies: The Key Concepts. (2nd edition). London: Routledge.

Ashcroft, B. (2001). Post-Colonial Transformation. London \& New York: Routledge.

Badiou, A. (2009). Logics of Worlds: Being and Event II. (Alberto Toscano, Trans.). London: Continuum.

Bauman, Z. (2000). Liquid Modernity. London: Polity.

Bhabha, H. K. (1994). The Location of Culture. London, Routledge.

---. (1996). "Cultures in Between," in S. Hall and P. Du Gay (Eds), Questions of Cultural Identity. London, Sage Publications.

---. (2006). "Cultural Diversity and Cultural Differences," in B. Ashcroft, G. Griffiths, and H. Tiffin (Eds.), The Post-Colonial Studies Reader (pp. 155-157). New York: Routledge.

Clifford, J. (1992). "Traveling cultures," in L. Grossberg, C. Nelson, and P. Treichler (Eds.), Cultural Studies (pp. 96-116). London: Routledge.

Erni, J. N. (2015). "Citizenship Management: On the Politics of Being Included-out." International Journal of Cultural Studies, 18(2): 1-18. DOI: 10.1177/1367877915573772

Friedman, S. S. (1998). Mappings: Feminism and the Cultural Geographies of Encounter. Princeton, New Jersey: Princeton University Press.

Gilroy, P. (1993). The Black Atlantic: Modernity and Double-Consciousness. Cambridge: Harvard University Press. .

Hall, S. (1990). "Cultural identity and diaspora," in J. Rutherford (Ed.), Identity: Community, Culture, Difference. (pp.155-157). London: Lawrence and Wishart.

Harris, J. (2013, July 29). "Serco: the company that is running Britain." The Guardian. Retrieved from URL: https://www.theguardian.com/business/2013/jul/29/serco-biggest-company-never-heardof

Hoogvelt, A. (1997). Globalization and the Postcolonial World: The New Political Economy of Development. Baltimore: The John Hopkins University Press.

Ingulfsen, I. (2016, February 18). "Why aren't European feminists arguing against the anti-immigrant right?" Open Democracy. Retrieved from URL: https://www.opendemocracy.net/5050/why-areeuropean-feminists-failing-to-strike-back-against-anti-immigrant-right

Lacan, J. (1966). Ecrits: A Selection. (Alan Sheridan, Trans). New York: W.W. Norton \& Co, 1977, 77. 
Marcus, S. (1992). "Fighting Bodies, Fighting Words: A Theory and Politics of Rape Prevention," in J. Butler and J. W. Scott (Eds.), Feminists Theorize the Political. London and New York: Routledge.

McClintock, A. (1997). "No Longer in a Future Heaven': Gender, Race, and Nationalism," in A. McClintock, A. Mufti, and E. Shohat (Eds.), Dangerous Liaisons: Gender, Nation, and Postcolonial Perspectives (pp. 89-112). Minneapolis: University of Minnesota Press.

Mohanty, S. P. (1989). "Us' and 'Them:' On the Philosophical Bases of Political Criticism." Yale Journal of Criticism 2.2. pp. 1-31.

Ohtani, E. (2014, December 15). "Detention Knows No Borders." Open Democracy. Retrieved from URL: https://www.opendemocracy.net/5050/eiri-ohtani/detention-knows-no-borders

---. (2015, March 3). "Immigration detention: 'expensive, ineffective and unjust."' Open Democracy. Retrieved from URL: https://www.opendemocracy.net/5050/eiri-ohtani/immigration-detentionexpensive-ineffective-and-unjust

Pratt, M. L. (1992). Imperial Eyes: Travel Writing and Transculturation. London: Routledge.

Puhl, J. (2015, 15 September). "Fortress Hungary: Orban Profits from the Refugees." Spiegel Online. Retrieved from URL: http://www.spiegel.de/international/europe/viktor-orban-wants-to-keepmuslim-immigrants-out-of-hungary-a-1052568.html

Shohat, E. (1992). "Notes on the Post-Colonial." Social Text 10:2-3 (31-2). pp. 99-113.

Women for Refugee Women (2014). Detained.

---. (2015). I Am Human.

Young, R. J. C. (1995). Colonial Desire: Hybridity in Theory, Culture and Race. London: Routledge. 